\title{
Estimating soil total nitrogen in smallholder farm settings using remote sensing spectral
} indices and regression kriging

Yiming Xu ${ }^{\mathrm{abbc},{ }^{*},}$, Scot E. Smith ${ }^{\mathrm{b}, \mathrm{c}}$, Sabine Grunwald ${ }^{\mathrm{b}, \mathrm{d}}$,

${ }^{a}$ Department of Environmental Science and Engineering, Beijing Technology and Business

6 University, Beijing 100048, China. Email: xuyimi@ufl.edu

7 b ${ }^{\mathrm{b}}$ School of Natural Resource and Environment, University of Florida, 103 Black Hall, PO Box

8 116455, Gainesville FL 32611, USA.

$9 \quad{ }^{\mathrm{c}}$ School of Forest Resources and Conservation - Geomatics Program, University of Florida, 301

10 Reed Lab, PO Box 110565, Gainesville, FL 32611-0565, USA. Email: sesmith@ufl.edu

$11{ }^{\mathrm{d}}$ Pedometrics, Landscape Analysis and GIS Laboratory, Soil and Water Sciences Department, 12 University of Florida, 2181 McCarty Hall, PO Box 110290, Gainesville FL 32611, USA. Email:

13 sabgru@ufl.edu

$14{ }^{\mathrm{e}}$ Gulf Coast REC / School of Forest Resources and Conservation - Geomatics Program, 15 University of Florida, 1200 N. Park Road, Plant City, FL 33563, USA. Email: aamr@ufl.edu

$16{ }^{\mathrm{f}}$ International Crops Research Institute for the Semi-Arid Tropics (ICRISAT), Patancheru

17 502324, Hyderabad, India. Email: s.wani@cgiar.org

$18{ }^{\mathrm{g}}$ Soil and Water Sciences Department, 2181 McCarty Hall, PO Box 110290, University of 19 Florida, Gainesville, Florida 32611. Email: vdn@ufl.edu

20 *Corresponding author at: Department of Environmental Science and Engineering, Beijing 21 Technology and Business University, Beijing 100048, China

\section{Abstract}

Mapping soil nutrients can help smallholder farmers identify soil nutrient status and

25 implement site-specific soil management schemes. In the past, Digital Soil Mapping has seldom

26 been utilized to guide soil nutrient management in smallholder farm settings in South India. The

27 objective of this research was to analyze the spatial resolution effects of different remote sensing

28 images on soil Total Nitrogen (TN) prediction models in two smallholder villages, Kothapally

29 and Masuti in South India. Regression kriging (RK) was used to characterize the spatial pattern 
30 of $\mathrm{TN}$ in the topsoil $(0-15 \mathrm{~cm})$ by incorporating spectral indices with different spatial resolutions.

31 The results suggested that soil moisture, vegetation, and soil crusts can contribute to the

32 conservation of soil $\mathrm{TN}$ in both study areas. Soil prediction models with different spatial

33 resolutions showed a similar spatial pattern of soil TN. The results also demonstrated that the

34 effect of very fine spatial remote sensing spectral data inputs does not always lead to an increase

35 of soil prediction model performance. A RapidEye-based $(5 \mathrm{~m})$ soil TN prediction model had

36 lower prediction accuracy than a Landsat 8-based $(30 \mathrm{~m})$ soil $\mathrm{TN}$ prediction model in Masuti.

37 WorldView-2/GeoEye-1/Pleiades-1A-based $(2 \mathrm{~m})$ soil TN prediction models had the highest

38 prediction accuracy in both study areas. The spectral indices based on new bands of WorldView-

392 such as coastal, yellow, red edge, and new near infrared bands had relatively strong

40 correlations with soil TN. The utilization of Very High Spatial resolution images such as

41 WorldView-2 in Digital Soil Mapping could improve soil model performance and spatial

42 characterization. Remote sensing-based soil prediction models have high potential to be widely

43 applied in smallholder farm settings.

44

45 Keywords: Digital Soil Mapping; Remote sensing; Smallholder farm; South India; Soil total 46 nitrogen; Spatial resolution

47

48 1. Introduction

49 Low and erratic precipitation, drought stress, high temperatures, low biomass, and low

50 soil productivity have major impacts on crop yields in arid and semi-arid farmland in South India

51 (Srinivasarao et al., 2013). Soil nutrient storage is essential and important in semi-arid tropical

52 soils, especially those that are used to maintain food security and soil security in smallholder

53 farm settings. Unlike research focusing on soil sampling and traditional soil laboratory analysis 
54 (Ouyang et al., 2013; Venkanna et al., 2014), Digital soil mapping (DSM) utilizes categorical

55 and continuous environmental variables to predict soil properties on multiple scales (McBratney

56 et al., 2003; Xu et al., 2017) and is more practical, economical, and suitable for sustainable soil

57 management. However, the application of Digital Soil Mapping (DSM) in smallholder farm

58 settings worldwide is only in its beginning stages due to lack of financial and technical support

59 and historical datasets.

60 Remote sensing images can provide soil-landscape information such as soil moisture

61 (Bertoldi et al., 2014), vegetation indices (Kross et al., 2015), and land surface temperature

62 (Weng et al., 2014), and are widely utilized in DSM research (Gray et al., 2016; Nigel and

63 Rughooputh, 2010). The past few decades have seen the emergence of various new remote

64 sensing products, which can provide soil-landscape information at various scales. Remote

65 sensing images such as Landsat 8 images $(30 \mathrm{~m})$ are easily obtained throughout the world.

66 Commercial remote sensing satellites such as WorldView-2 $(2 \mathrm{~m})$ and SPOT $5(10 \mathrm{~m})$ also

67 provide detailed landscape information at relatively fine spatial resolution. As a result, there is a

68 trade-off between choosing fine spatial resolution and coarse spatial resolution remote sensing

69 imagery in DSM.

70 Some research has indicated advantages to the use of fine spatial resolution images for

71 soil prediction in terms of error assessment and accuracy (Sumfleth and Duttmann, 2008;

72 Vaudour et al., 2013). Other research demonstrated that the highest spatial resolution

73 environmental variables may not always produce the most accurate soil prediction. According to

74 Schmid et al. (2008), ASTER images (30 m) have longer spectral domain and more bands than

75 IKONOS images $(4 \mathrm{~m})$. They also have higher prediction capability than IKONOS images in

76 predicting soil classes. Kim and Zheng (2011) demonstrated that fine scale topographic 
77 information is not always optimal for understanding soil spatial variability. However, there has

78 been little research analyzing the effects of remote sensing spectral indices with fine to medium

79 spatial resolution ( $2 \mathrm{~m}$ to $30 \mathrm{~m}$ ) on soil prediction models in regions such as smallholder farm

80 settings.

81 Unlike ordinary kriging, regression kriging includes deterministic and stochastic

82 components (Hengl et al., 2007). The deterministic component is often a multi-linear regression

83 model between the target soil property and auxiliary environmental variables such as vegetation

84 indices and land use types (Samuel-Rosa et al., 2015). The stochastic component is a spatially

85 correlated random field of residuals from the deterministic component. This spatially correlated

86 random component is usually fitted by variogram and interpolated by ordinary regression (Mora-

87 Vallejo et al., 2008). Regression kriging has been widely applied in the DSM domain (Kuriakose

88 et al., 2009; Mishra et al., 2012; Sun et al., 2012), and has attained better prediction results

89 compared with ordinary kriging (Hengl et al., 2007; Mirzaee et al., 2016). The objectives of this

90 research were to : 1) characterize the spatial pattern of soil Total Nitrogen (TN) in two

91 smallholder villages, Kothapally and Masuti, South India and 2) test and evaluate the spatial

92 resolution effects of spectral indices from Landsat 8 (30 m), RapidEye (5 m), and WorldView-

93 2/GeoEye-1/Pleiades-1A ( $2 \mathrm{~m})$ on soil TN prediction models in both study areas.

\section{2. Material and methods}

\section{2.1. Description of the study areas}

96 Kothapally is a smallholder village located in Ranga Reddy District, Telangana State,

97 India (Fig. 1). It experiences a hot and dry semi-arid climate with an annual rainfall of $802 \mathrm{~mm}$

98 (Sreedevi et al., 2004). Cotton (Gossypium hirsutum) and rice (Oryza sativa) are the major crops

99 planted in the rainy season. Sorghum (Sorghum bicolar) is the predominant crop type in the dry

100 season. The monsoon season is from June to September with the precipitation averaging $755 \mathrm{~mm}$. 
101 Vertisols are the major soil type in Kothapally. A detailed description of Kothapally is given by 102 Xu et al. (2017).

103 Masuti is another smallholder village located in Basavana Bagevadi Tehsil, Bijapur

104 District, Karnataka State, located in South India (Fig. 1). It is $513 \mathrm{~km}$ from the state capital,

105 Bangalore. It also experiences a semi-arid climate with temperature variations between $20^{\circ} \mathrm{C}$ and

$10642^{\circ} \mathrm{C}$. The annual rainfall ranges from 569 to $595 \mathrm{~mm}$. The soils in this area vary between dark

107 grayish brown and dark brown to dark reddish brown. Soil texture varies from loam to clay

108 according to investigation by the International Crops Research Institute for the Semi-Arid

109 Tropics (ICRISAT). Sorghum (Sorghum bicolar), tomato (Lycopersicon esculentum var.

110 esculentum), and onion (Allium cepa) are the three major crops in the dry season. Cotton

111 (Gossypium hirsutum), rice (Oryza sativa), and maize (Zea mays) are the three major crops in the

112 rainy season.

\section{2.2. Soil sampling and laboratory analysis}

114 Soil samples were divided into four classes (green, dark, light, and intermediate areas)

115 based on unsupervised classification application in the ERDAS 2011 software (Earth Resource

116 Data Analysis System Inc., Atlanta, GA). Based on the four classes of soil, a stratified random

117 sampling method was performed in ArcMap 10 (Environmental Systems Resource Institute,

118 ArcMap 10.0 ESRI, Redlands, California) using the "SamplingTool_10" (NOAA/Biogeography

119 Branch, 2012) add-in. In total, 255 soil samples at 0-15 $\mathrm{cm}$ were collected in Kothapally in May

120 2012, and 259 soil samples at 0-15cm were collected in Masuti from February to March 2013 by

121 the ICRISAT and the University of Florida (Fig. 1). Geographic attributes of each soil sample

122 point such as $\mathrm{x}$ and y coordinates, were obtained from a Differential Global Positioning System

123 (DGPS) with sub-meter accuracy (Trimble Navigation Ltd., Sunnyvale, California, USA). GPS

124 post-correction was performed by Aimil Ltd. (www.aimil.com) in Hyderabad, India. Site- 
125 specific descriptions, including soil types, crop types, soil color and tillage methods, were

126 recorded at each sampling point. After air-drying for one week, all the soil samples in both study

127 areas were sieved through a 2-mm sieve, then analyzed for soil TN based on a concentration

128 basis $\left(\mathrm{mg} \mathrm{kg}^{-1}\right)(\mathrm{Krom}, 1980)$ in ICRISAT.

129 2.3. Remote sensing data collection and processing

130 Cloud-free satellite remote sensing imagery, including one WorldView-2 image (2 m),

131 one GeoEye-1 image ( $2 \mathrm{~m}$ ), two RapidEye images (5 m), and two Landsat 8 images (30 m) in

132 Kothapally, and one WorldView-2 image, one Pleiades-1A image (2 m), two RapidEye images,

133 and two Landsat 8 images in Masuti, were acquired to extract environmental variables in soil TN

134 prediction models (Table 2). Advanced Spaceborne Thermal Emission and Reflection

135 Radiometer (ASTER) Global Digital Elevation Model (DEM) data were obtained in order to

136 extract topographic attributes in both study areas. Table 2 lists all the satellite remote sensing

137 images in the two study areas.

138 The original pixel values of raw remote sensing images are Digital Numbers (DNs).

139 Radiometric calibration was applied to transform the DNs to top-of-atmosphere spectral radiance

140 using different algorithms depending on the remote sensing products. Atmospheric correction

141 was utilized to convert all the spectral radiance images into surface reflectance images using the

142 Fast Line-of-Site Atmospheric Analysis of Spectral Hypercubes (FLAASH) tool in the ENVI 5.0

143 software (Exelis Visual Information Solutions, Boulder, Colorado).

144 2.4. Spectral indices extraction

145 Multiple spectral indices were extracted from Landsat 8, RapidEye, WorldView-2,

146 GeoEye-1 and Pleiades-1A in the two study areas. Topographic attributes such as elevation (m),

147 slope (degree), aspect (degree), flow direction, and flow accumulation were extracted from the

148 ASTER Global DEM. Table 3 lists all the environmental variables including spectral indices, 
149 topographic attributes and geographic attributes in this research. Selected environmental

150 variables were incorporated into the soil TN prediction models.

\section{$151 \quad$ 2.5. Regression kriging}

152 The ordinary kriging method predicts the soil property by calculating the weighted

153 average of the observations (Webster and Oliver, 2001):

$154 \hat{Z}\left(s_{0}\right)=\sum_{i=1}^{n} \lambda_{i} * z\left(s_{i}\right)$

155 where $\hat{z}\left(s_{0}\right)$ is the predicted value of the target soil properties at an unvisited location $s_{0}$, given

156 its coordinates, the sample $z\left(s_{0}\right), z\left(s_{0}\right), \ldots, z\left(s_{0}\right)$, and their coordinates. The weights $\lambda_{i}$ are

157 chosen such that the prediction error variance is minimized, yielding weights that depend on the

158 spatial autocorrelation structure of the variable.

159 The regression approach predicts the soil property by modelling the relationship between

160 the target soil property and auxiliary environmental variables (e.g. spectral indices) at soil

161 sampling locations and, then applying it to unvisited locations using the known value of the

162 auxiliary variables at those locations (Hengl et al., 2007). Multiple linear regression was used to

163 model the relationships between soil $\mathrm{TN}$ and spectral indices from different remote sensing

164 images.

165 Regression kriging (Hengl et al., 2007) combines these two approaches: multiple linear

166 regression is used to fit the explanatory variables, and ordinary kriging is used to fit the residuals

167 of the multiple linear regression:

168

$$
\hat{z}\left(s_{0}\right)=\widehat{m}\left(s_{0}\right)+\hat{e}\left(s_{0}\right)=\sum_{k=0}^{p} \beta_{k} * q_{k}\left(s_{0}\right)+\sum_{i=1}^{n} \lambda_{i} * e\left(s_{i}\right)
$$

where $\widehat{m}\left(s_{0}\right)$ is the fitted drift, $\hat{e}\left(s_{0}\right)$ is the interpolated residual, $\beta_{k}$ are the estimated

170 regression coefficients, $q_{k}\left(s_{0}\right)$ are the values of the environmental variables, and $\mathrm{p}$ is the number

171 of predictors or environmental variables. $\lambda_{i}$ are the kriging weights determined by the spatial 
172 dependence structure of the residual, and $e\left(s_{i}\right)$ is the residual at location $s_{i}$. The regression

173 coefficients $\beta_{k}$ are estimated from the sample by ordinary least squares (OLS) in this study.

174 Several R software (R Development Core Team, 2014) packages such as sp, gstat, geoR,

175 rgdal, maptools, and lattice, were utilized to build the regression kriging models and map soil TN.

$176 \quad$ 2.6. Validation of model accuracy

177 For each soil TN prediction model, all the soil sampling points were randomly split into a

178 calibration set (70\%, Kothapally: 179 points, Masuti: 76 points) for model calibration and a

179 validation set (30\%, Kothapally: 180 points, Masuti: 79 points) for independent model validation.

180 The Kolmogorov-Smirnov test was applied for the soil calibration and validation sets to ensure

181 that they had the same distribution. A log-transformation was applied to the whole soil dataset,

182 calibration soil data set, and validation soil dataset to ensure the normal distribution of soil data.

183 The coefficient of determination $\left(\mathrm{R}^{2}\right)$, root mean squared error (RMSE), and residual prediction

184 deviation (RPD) (Bellon-Maurel et al., 2010) were computed using R software and used to 185 compare different regression kriging models.

186 3. Results

187 3.1. Descriptive analysis of soil TN

188 Descriptive analysis of soil TN and log-transformed soil TN is shown in Table 4. TN

189 showed a positive-skewed distribution, with a mean of $869 \mathrm{mg} \mathrm{kg}^{-1}$, a median of $856 \mathrm{mg} \mathrm{kg}^{-1}$,

190 and a range of $1492 \mathrm{mg} \mathrm{kg}^{-1}$ in Kothapally. Total nitrogen showed a positive-skewed distribution,

191 with a mean of $514 \mathrm{mg} \mathrm{kg}^{-1}$, a median of $487 \mathrm{mg} \mathrm{kg}^{-1}$, and a range of $1016 \mathrm{mg} \mathrm{kg}^{-1}$ in Masuti.

192 The mean of soil TN is lower in Masuti compared to that in Kothapally. After the log-

193 transformation, all the datasets (whole, calibration, and validation) of soil TN were Gaussian

194 distributed in the two study areas. 

214 TN.

\section{3.3. Multiple linear regression models}

Six multiple linear regression models between log-transformed TN (calibration soil data 218 Table 6. All six multi-linear regression models showed relatively low coefficients of

\subsection{Correlation coefficients between soil $\mathrm{TN}$ and spectral indices from different remote sensing images}

Table 5 shows Spearman's rank correlation coefficients between soil TN and spectral indices from different remote sensing images. The Atmospherically Resistant Vegetation Index (ARVI) and Crust Index (CI) from Landsat 8, RapidEye, WorldView-2, GeoEye-1, and Pleiades1A showed positive correlations with $\mathrm{TN}$ in both study areas. Near-infrared-related spectral indices from all remote sensing images, such as Normalized Difference Vegetation Index (NDVI), Simple Ratio (SR) and Transformed Spectral Index (TVI), and red-edge-related spectral indices from WorldView-2 and RapidEye, such as Normalized Difference Red-edge Index (NDVIr) and Red-edge Chlorophyll Index (CIr), as well as the band ratio between NIR band 2 to red-edge (N2RE), showed relatively strong positive correlations with TN in both study areas. Band ratios such as red to green (RG), red to blue (RB), and short wavelength (SWIR) band 2 to SWIR band 1 (S2S1), as well as the band reflectances such as red band (Red), yellow band (Yellow) and blue band (Blue) from remote sensing images showed relatively strong negative correlations with TN in both study areas. Bare soil indices such as the Bare Soil Index (BSI) and Normalized Difference Soil Index (NDSI) from Landsat 8 showed relatively strong negative correlations with TN in both study areas. Thermal band-related spectral indices from Landsat 8 such as at-satellite brightness temperature for thermal band $1(10.30-11.30 \mu \mathrm{m})(\mathrm{T} 1)$ and thermal band $2(11.50-12.50 \mu \mathrm{m})(\mathrm{T} 2)$ also showed relatively strong negative correlations with set) and spectral indices in Kothapally (K1, K2, K3), and in Masuti (M1, M2, M3) are shown in 
219 determination $(<0.3)$. Ordinary kriging was performed on the residuals of the six multiple linear

220 regression models. Six regression kriging models of TN based on the multiple linear regression

221 models in Kothapally (KR1, KR2, and KR3) and Masuti (MR1, MR2, and MR3) were built to

222 predict soil TN and characterize the spatial pattern of TN in both study areas (Table 7).

\section{3.4. Characterization of soil $\mathrm{TN}$ in smallholder farms}

\section{3.4.1. Spatial pattern of $\mathrm{TN}$ at different spatial resolutions in Kothapally}

225 Spatial variations of soil TN in Kothapally generally showed a similar pattern in three

226 maps in Fig. 2. Total nitrogen in the southwestern and northern areas of the village was relatively

227 lower compared with other areas. The east-west strip areas in the center of the village and the

228 southeastern area of the village had relatively higher TN. TN variation based on Landsat 8 229 images (Fig. 2 (A)) was smoother than in the other two maps in Fig. 2. The finer characterization 230 of the TN pattern exemplified the advantages of model KR3 (Fig. 2 (C)) based on WorldView-2 231 and GeoEye-1 spectral indices in depicting the TN pattern in small farmlands.

232 Spatial variation of soil TN in Farmland A (a small farmland in Kothapally)

233 demonstrated the similarities and differences of the three models more clearly (Fig. 3). Generally,

234 Fig. 3 (A), (B), and (C) showed relatively low TN in the northwestern and southeastern areas of

235 Farmland A and relatively high TN from the southwest to northeast across Farmland A. Fig. 3 (A) 236 generalized the TN distribution, and it may mix the spatial pattern of TN in different field blocks

237 owned by many farmers. Fig. 3 (B) had a higher capability to detect the fine variations in

238 Farmland A, such as the fragmented TN pattern across the Farmland A. Fig. 3 (C) showed the 239 evident rectangular patchy pattern of TN in each field block, the linear low TN pattern in the 240 western area of Farmland A, and subtle variations of TN in each field block.

\section{3.4.2. Spatial pattern of $T N$ at different spatial resolutions in Masuti}


243 patterns (Fig. 4). Total nitrogen was relatively higher in the southwestern area of the village

244 compared with other areas (Fig. 4). An irrigation channel was located in this region that it may

245 bring more water and increase soil moisture in the region. Total nitrogen was relatively low in

246 the northern area of the village where most of the area was permanently fallow, and the main soil

247 types were Entisols according to the ICRISAT. Venkanna et al. (2014) also concluded that TN

248 was higher in cultivated fields than in permanently fallow soils, and higher under irrigated

249 conditions than under rainfed conditions in the semiarid region of South India. The farmland

250 close to a dam in the north-central area of the village also had relatively high TN. Vertisols are

251 the main soil type in the southern area of the village, and this soil type is rich in montmorillonite

252 clay and has a relatively high exchangeable buffering capacity in South India (Krishna, 2010).

253 Venkanna et al. (2014) and Srinivasarao et al. (2009) also indicated that soil organic carbon and

254 soil nitrogen are relatively higher in Vertisols than in other soil types in South India. As a result,

255 the TN in the southern area of the village was relatively higher than in the northern area of the

256 village. Unlike the homogeneous and smooth variation of TN in the $30 \mathrm{~m}$ map produced by MR1

257 (Fig. 4 (A)), there is a heterogeneous and fragmented spatial variation of $\mathrm{TN}$ in the $2 \mathrm{~m}$ map

258 produced by model MR3 (Fig. 4 (C)). Fig. 4 (A) showed a large continuous area in the northern

259 area of the village containing TN at lower concentrations than $400 \mathrm{mg} \mathrm{kg}^{-1}$. However, Fig. 4 (B)

260 and Fig. 4 (C) revealed a mosaicked spatial pattern of TN in the northern area of the village.

261 Fig. 5 shows the prediction for TN in Farmland B (a small farmland in Masuti). All three

262 maps in Fig. 5 show relatively low TN in the northern and southeastern Farmland B, and

263 relatively high TN in the western Farmland B. The Landsat 8-based TN map (Fig. 5 (A)) only

264 showed a few pixels. The RapidEye-based TN map (Fig. 5 (B)) identified high TN in the 
265 northern area of Farmland B and a more detailed TN pattern. The WorldView-2/Pleiades-1A-

266 based TN map (Fig. 5 (C)) characterized the gradient variation and fragmented pattern of TN in

267 Farmland B, which demonstrated the paramount advantages of Model MR3 in displaying the TN

268 in different field blocks and depicting the subtle variation of TN in each field block.

\section{3.4.3. Validation of regression kriging model for $\mathrm{TN}$}

Table 7 shows the validation results of soil TN prediction models in both study areas. In

271 Kothapally, the RK model of TN based on WorldView-2 and GeoEye-1 images (KR3) attained

272 the highest model fit $\left(\mathrm{R}^{2}=0.42\right)$ and lowest prediction error ( $\left.\mathrm{RMSE}=159.36 \mathrm{mg} \mathrm{kg}^{-1}\right)$ compared

273 with the RK models of TN based on Landsat 8 (KR1) and RapidEye (KR2). In Masuti, the

274 Landsat 8-based model MR1 can still attain fair prediction accuracy $\left(\mathrm{R}^{2}=0.48\right.$; RMSE $=146.24$

$275 \mathrm{mg} \mathrm{kg}^{-1}$ ) regardless of its relatively coarse spatial resolution (30 m). RapidEye-based model MR2

276 attained lower prediction accuracy $\left(\mathrm{R}^{2}=0.41\right.$; $\left.\mathrm{RMSE}=148.70 \mathrm{mg} \mathrm{kg}^{-1}\right)$ compared with Landsat 8-

277 based model MR1. Model MR3 based on WorldView-2 and Pleiades-1A attained the highest

278 prediction accuracy $\left(\mathrm{R}^{2}=0.56\right.$; RMSE $\left.=130.73 \mathrm{mg} \mathrm{kg}^{-1}\right)$.

279 4. Discussion

280 4.1. Spectral indices with different spatial resolutions

281 The reflectance of vegetation was low in both blue and red spectrum regions due to the

282 absorption by chlorophyll for photosynthesis. In contrast, the reflectance of bare soil increased 283 steadily in the visible and near-infrared (VNIR) spectral region. Most research has already 284 confirmed that the visible band spectral reflectances of bare soils are higher than those of 285 vegetated areas (Holben, 1986), and the visible band spectral reflectances of relatively dry soils 286 are higher than those of relatively wet soils (Fabre et al., 2015). The strong negative relationship 287 between visible band reflectances and soil TN suggested that less vegetated areas tend to have 288 less soil TN than richly vegetated areas, and drier soils tend to have less soil TN than wetter soils. 
289 The Crust Index (CI) and ARVI of different remote sensing images all showed relatively strong 290 positive correlations with TN. As soil crusts contribute to soil stability, soil build-up, soil fertility, 291 and soil water regime in arid and semi-arid areas, the strong positive relationship between CI and 292 TN confirmed the importance of soil crust for soil TN conservation in the study areas. ARVI, 293 which uses the difference in the radiance between the blue and the red channels to correct the 294 radiance in the red channel, is four times less sensitive to atmospheric conditions compared to 295 NDVI (Kaufman and Tanre, 1992). Red-edge measurement is valuable for the assessment of 296 vegetative chlorophyll status and leaf area index independent of ground cover variations (Horler 297 et al., 1983; Mutanga and Skidmore, 2004). The strong correlations between red edge-related 298 indices (e.g., NDVIr and red-edge spectral reflectances) and soil TN in both study areas also 299 suggested that those indices have strong predictive capability in soil TN prediction models in 300 South India.

301 Spectral indices from SWIR have the potential to provide information about soil moisture 302 conditions, as water has pronounced absorption features in the SWIR region (van der Meer, 303 2004). This suggests that the soil water can increase the absorption of SWIR and decrease the 304 reflectance in SWIR region. The strong negative relationship between soil TN and SWIR 305 reflectances suggests the accumulation of soil TN in low SWIR reflectance areas (wet soils or 306 vegetation areas). The results of Musick and Pelletier (1988) showed that the Mid-infrared Index 307 (MidIR, band ratio of SWIR band 1 to SWIR band 2) had a positive relationship with soil water 308 content. The relatively strong positive relationship between the MidIR from Landsat 8 and TN 309 demonstrated the importance of soil water content in retaining soil TN in this area.

310 The negative correlations between Thermal infrared (TIRS) indices, such as at-satellite

311 brightness temperatures of thermal bands (band 10 and band 11) from Landsat 8 and TN 
312 suggested that soils with relatively lower at-satellite brightness temperatures (higher water

313 content) were likely to contain higher TN than soils with relatively higher at-satellite brightness

314 temperatures (lower water content). Many researchers have also tried to estimate soil moisture

315 from at-satellite brightness temperature data using multiple algorithms (Paloscia et al., 2006;

316 Song et al., 2014).

317 Due to the limited remote sensing images in the two study areas, there is a discrepancy

318 between the acquisition date of the remote sensing images and soil collection time. This problem

319 may explain the low correlations between some spectral indices and soil TN in Table $5(<0.4)$.

320 The spectral behavior of the spectral indices from different remote sensing images is similar. For

321 example, the ARVI and CI from remote sensing images in both study areas all had relatively

322 strong positive correlations with $\mathrm{TN}$. The spectral reflectances and band ratios from remote 323 sensing images in both study areas all had relatively strong negative correlations with TN. These

324 results suggested the transferability of important spectral indices in soil prediction models in

325 different semi-arid smallholder farms. The correlation relationships between multiple spectral

326 indices and soil TN also suggested that soil moisture, vegetation, and soil crusts could contribute

327 to the conservation of soil TN in both study areas. In all, the Crust Index, which showed the soil

328 crust, NIR band-related and red-edge band-related vegetation indices, which reflected the

329 vegetation cover and biomass, and band reflectances and band ratios, which indicated the soil

330 moistures, were the indices that displayed relatively strong correlations with $\mathrm{TN}$ and were

331 included in the regression model (Table 6).

332 4.2. Selection of remote sensing images for Digital Soil Mapping in smallholder farms

333 Due to the wider spectral range and larger number of spectral bands of the Landsat 8

334 images, spectral indices from the visible-NIR-SWIR-TIR spectrum region can provide spectral

335 information about soil moisture, vegetation and soil temperature, which affect the spatial pattern 
336 of soil properties. In addition, Landsat 8 has higher temporal resolution than commercial

337 satellites and can reflect multi-period soil-landscape information. As a result, models KR1 and

338 MR1 can still attain fair prediction results at a relatively low spatial resolution (30 m). Due to the

339 availability of freely available remote sensing images such as Landsat and Sentinels, the

340 application of DSM in data poor regions such as smallholder farms can be promoted with little

341 human and financial support.

342 The application of Very High Resolution (VHR) remote sensing images in the DSM

343 domain in smallholder farms is in its infancy. The comparison of soil prediction models based on

344 different remote sensing images also suggested that the spectral indices from VHR remote

345 sensing did not necessarily result in higher prediction accuracy for soil prediction models

346 compared with those from medium resolution remote sensing data. For example, the prediction

347 accuracy of Model MR2, based on RapidEye was lower than that of Model MR1, based on

348 Landsat 8 . The spatial pattern of soil properties such as TN in smallholder farm settings may also

349 be affected by micro-scale topographic attributes and human agricultural practices. These factors

350 cannot be captured in their entirely by even fine resolution spectral indices.

351 The complexity and variation of TN in Kothapally (Fig. 2 (C)) and Masuti (Fig. 4 (C))

352 confirmed that the soil prediction models based on WorldView-2, GeoEye-1 and Pleiades-1A

353 have paramount advantages over other models in depicting the subtle variation of soil properties

354 in small farmlands. WorldView-2/GeoEye-1/Pleiades-1A-based soil TN prediction models

355 attained the highest model accuracy $\left(\mathrm{R}^{2}>0.4\right)$ in both study areas. WorldView-2 images have a

356 red-edge band $(705-745 \mathrm{~nm})$, a new NIR band $(860-1040 \mathrm{~nm})$ and finer spatial resolution

357 compared with other images. The WorldView-2 image is the first sensor to include the yellow,

358 red-edge, coastal, two separate NIR and traditional visible bands in a single focal plane (Wolf, 
359 2010). The new coastal band has the potential to produce more spectral indices to reflect subtle

360 moisture differences, such as soil and surface moisture levels, which are not exploitable by

361 traditional Visible-NIR multispectral images (Wolf, 2010). These VHR remote sensing spectral

362 indices can capture more detailed and unmixed spectral and spatial information in fine landscape 363 agricultural fields.

\section{4.3 Site-specific soil management schemes based on DSM in smallholder farms}

365 To help smallholder farmers identify the soil nutrient status in their fields, it is important

366 to map soil nutrients such as soil TN in smallholder villages. Soil TN prediction models only

367 incorporating remote sensing spectral indices can still attain fair prediction accuracy. This

368 research suggests that digital soil models utilizing remote sensing spectral indices from Landsat

3698 have a high potential to be widely applied in smallholder farms due to the free acquisition of

370 the images, fine temporal resolution, and fair model performance. Digital soil models utilizing

371 Very High Resolution (VHR) images such as WorldView-2 and Pleiades-1A have a strong

372 capability to characterize the spatial pattern of soil properties in fine scale farmland and provide

373 more site-specific soil recommendations in smallholder farms, due to the fine spatial resolution

374 and fair model performance. As commercial satellites usually required image purchases and

375 more processing time and have limited image acquisitions, the wide application of DSM research

376 based on VHR images in the smallholder farm settings is less practical. Agricultural experts,

377 policymakers and other end-users of DSM can choose different types of Very High Resolution

378 images as options for building soil prediction models, and guide the soil management in

379 smallholder farms according to financial budget and data availability.

380 In future research, hyperspectral images such as Hyperion, airborne visible/infrared

381 imaging spectrometer (AVIRIS) and Unmanned Aerial Vehicle (UAV)-based remote sensing 
382 products also have potential to be utilized in Digital Soil Mapping research and help smallholder

383 farmers implement field-specific soil nutrient management schemes.

\section{5. Conclusions}

385 The results demonstrated that soil moisture, vegetation, and soil crusts could contribute to

386 the conservation of soil TN in both study areas. Soil TN models with different spatial resolutions

387 showed similar spatial patterns of soil TN. The effect of very fine spatial remote sensing spectral

388 data inputs does not always lead to an increase in soil prediction model performance. This

389 research suggested that soil prediction models utilizing satellite imagery-derived spectral indices

390 from Landsat 8 have a high potential to be widely applied in smallholder farm settings due to the

391 free acquisition of images, high temporal resolution and relatively strong prediction capability.

392 Agricultural experts, policymakers and other end-users of DSM can choose different types of

393 Very High Resolution images as options for building soil prediction models, and guide soil

394 nutrient management in smallholder farms according to financial budget and data availability.

395

396 Acknowledgements

397 This work is supported by the grant award no. 1201943 "Development of a Geospatial Soil-Crop 398 Inference Engine for Smallholder Farmers" EAGER National Science Foundation and Research 399 Foundation for Youth Scholars of Beijing Technology and Business University. The soil analysis 400 was performed in the soil laboratory at the International Crops Research Institute for the Semi401 Arid Tropics (ICRISAT) in Patancheru/Hyderabad, India. We thank Christopher M. 402 Clingensmith at University of Florida, and other ICRISAT staff members and villagers of 403 Kothapally for support in field sampling. We also thank Yiming Xu's PhD committee member 404 Dr. Thomas K. Frazer for his commitment and guidance. A matching assistantship for Yiming 405 Xu was provided by the School of Natural Resources and Environment, University of Florida, 406 and the China Scholarship Council.

407

\section{References}


410

411

412

413

414

415

416

417

418

419

420

421

422

423

424

425

426

427

428

429

430

431

432

433

434

435

436

437

438

439

440

441

442

443

444

445

446

447

448

449

450

451

452

453

454

455

Adamczyk, J., Osberger, A., 2015. Red-edge vegetation indices for detecting and assessing disturbances in Norway spruce dominated mountain forests. International Journal of Applied Earth Observation and Geoinformation, Special Issue on Earth observation for habitat mapping and biodiversity monitoring 37, 90-99. doi:10.1016/j.jag.2014.10.013

Bellon-Maurel, V., Fernandez-Ahumada, E., Palagos, B., Roger, J.-M., McBratney, A., 2010. Critical review of chemometric indicators commonly used for assessing the quality of the prediction of soil attributes by NIR spectroscopy. TrAC Trends in Analytical Chemistry 29, 1073-1081. doi:10.1016/j.trac.2010.05.006

Bertoldi, G., Della Chiesa, S., Notarnicola, C., Pasolli, L., Niedrist, G., Tappeiner, U., 2014. Estimation of soil moisture patterns in mountain grasslands by means of SAR RADARSAT2 images and hydrological modeling. Journal of Hydrology, Determination of soil moisture: Measurements and theoretical approaches 516, 245-257. doi:10.1016/j.jhydrol.2014.02.018

Cohen, W.B., 1991. Response of vegetation indices to changes in three measures of leaf water stress. Photogrammetric Engineering and Remote Sensing 195-202.

Daughtry, C.S.T., Walthall, C.L., Kim, M.S., de Colstoun, E.B., McMurtrey III, J.E., 2000. Estimating Corn Leaf Chlorophyll Concentration from Leaf and Canopy Reflectance. Remote Sensing of Environment 74, 229-239. doi:10.1016/S0034-4257(00)00113-9

Fabre, S., Briottet, X., Lesaignoux, A., 2015. Estimation of Soil Moisture Content from the Spectral Reflectance of Bare Soils in the 0.4-2.5 $\mu$ m Domain. Sensors 15, 3262-3281. doi:10.3390/s150203262

Gao, B., 1996. NDWI-A normalized difference water index for remote sensing of vegetation liquid water from space. Remote Sensing of Environment 58, 257-266. doi:10.1016/S0034-4257(96)00067-3

Gitelson, A.A., Kaufman, Y.J., Merzlyak, M.N., 1996. Use of a green channel in remote sensing of global vegetation from EOS-MODIS. Remote Sensing of Environment 58, 289-298. doi:10.1016/S0034-4257(96)00072-7

Gitelson, A.A., Viña, A., Ciganda, V., Rundquist, D.C., Arkebauer, T.J., 2005. Remote estimation of canopy chlorophyll content in crops. Geophys. Res. Lett. 32, L08403. doi:10.1029/2005GL022688

Gitelson, A., Merzlyak, M.N., 1994. Spectral Reflectance Changes Associated with Autumn Senescence of Aesculus hippocastanum L. and Acer platanoides L. Leaves. Spectral Features and Relation to Chlorophyll Estimation. Journal of Plant Physiology 143, 286292. doi:10.1016/S0176-1617(11)81633-0

Gray, J.M., Bishop, T.F.A., Wilford, J.R., 2016. Lithology and soil relationships for soil modelling and mapping. CATENA 147, 429-440. doi:10.1016/j.catena.2016.07.045

Haboudane, D., Miller, J.R., Tremblay, N., Zarco-Tejada, P.J., Dextraze, L., 2002. Integrated narrow-band vegetation indices for prediction of crop chlorophyll content for application to precision agriculture. Remote Sensing of Environment 81, 416-426. doi:10.1016/S0034-4257(02)00018-4

Hengl, T., Heuvelink, G.B.M., Rossiter, D.G., 2007. About regression-kriging: From equations to case studies. Computers \& Geosciences, Spatial Analysis Spatial Analysis 33, 13011315. doi:10.1016/j.cageo.2007.05.001

Holben, B.N., 1986. Characteristics of maximum-value composite images from temporal AVHRR data. International Journal of Remote Sensing 7, 1417-1434. doi:10.1080/01431168608948945 
Horler, D. N. H., Dockray, M., \& Barber, J., 1983. The red edge of plant leaf reflectance. International Journal of Remote Sensing 4, 273-288. doi:10.1080/01431168308948546

Karnieli, A., 1997. Development and implementation of spectral crust index over dune sands. International Journal of Remote Sensing 18, 1207-1220. doi:10.1080/014311697218368

Kaufman, Y.J., Tanré, D., 1996. Strategy for direct and indirect methods for correcting the aerosol effect on remote sensing: From AVHRR to EOS-MODIS. Remote Sensing of Environment 55, 65-79. doi:10.1016/0034-4257(95)00193-X

Kaufman, Y.J., Tanre, D., 1992. Atmospherically resistant vegetation index (ARVI) for EOSMODIS. IEEE Transactions on Geoscience and Remote Sensing 30, 261-270. doi: $10.1109 / 36.134076$

Kim, D., Zheng, Y., 2011. Scale-dependent predictability of DEM-based landform attributes for soil spatial variability in a coastal dune system. Geoderma 164, 181-194. doi:10.1016/j.geoderma.2011.06.002

Krishna, K.R., 2010. Agroecosystems of South India: Nutrient Dynamics, Ecology and Productivity. Universal-Publishers.

Krom, M.D., 1980. Spectrophotometric determination of ammonia: a study of a modified Berthelot reaction using salicylate and dichloroisocyanurate. Analyst 105, 305-316. doi:10.1039/AN9800500305

Kross, A., McNairn, H., Lapen, D., Sunohara, M., Champagne, C., 2015. Assessment of RapidEye vegetation indices for estimation of leaf area index and biomass in corn and soybean crops. International Journal of Applied Earth Observation and Geoinformation 34, 235-248. doi:10.1016/j.jag.2014.08.002

Kuriakose, S.L., Devkota, S., Rossiter, D.G., Jetten, V.G., 2009. Prediction of soil depth using environmental variables in an anthropogenic landscape, a case study in the Western Ghats of Kerala, India. CATENA 79, 27-38. doi:10.1016/j.catena.2009.05.005

McBratney, A.B., Mendonça Santos, M.L., Minasny, B., 2003. On digital soil mapping. Geoderma 117, 3-52. doi:10.1016/S0016-7061(03)00223-4

Mirzaee, S., Ghorbani-Dashtaki, S., Mohammadi, J., Asadi, H., Asadzadeh, F., 2016. Spatial variability of soil organic matter using remote sensing data. CATENA 145, 118-127. doi:10.1016/j.catena.2016.05.023

Mishra, U., Torn, M.S., Masanet, E., Ogle, S.M., 2012. Improving regional soil carbon inventories: Combining the IPCC carbon inventory method with regression kriging. Geoderma 189-190, 288-295. doi:10.1016/j.geoderma.2012.06.022

Mora-Vallejo, A., Claessens, L., Stoorvogel, J., Heuvelink, G.B.M., 2008. Small scale digital soil mapping in Southeastern Kenya. CATENA 76, 44-53. doi:10.1016/j.catena.2008.09.008

Musick, H.B., Pelletier, R.E., 1988. Response to soil moisture of spectral indexes derived from bidirectional reflectance in thematic mapper wavebands. Remote Sensing of Environment 25, 167-184. doi:10.1016/0034-4257(88)90099-5

Mutanga, O., Skidmore, A.K., 2004. Narrow band vegetation indices overcome the saturation problem in biomass estimation. International Journal of Remote Sensing 25, 3999-4014.

Nellis, M.D., Briggs, J.M., 1992. Transformed Vegetation Index for Measuring Spatial Variation in Drought Impacted Biomass on Konza Prairie, Kansas. Transactions of the Kansas Academy of Science (1903-) 95, 93-99. doi:10.2307/3628024 
500

501

502

503

504

505

506

507

508

509

510

511

512

513

514

515

516

517

518

519

520

521

522

523

524

525

526

527

528

529

530

531

532

533

534

535

536

537

538

539

540

541

542

543

544

Nigel, R., Rughooputh, S.D.D.V., 2010. Soil erosion risk mapping with new datasets: An improved identification and prioritisation of high erosion risk areas. CATENA 82, 191205. doi:10.1016/j.catena.2010.06.005

Oliver, M.A., Webster, R., 2014. A tutorial guide to geostatistics: Computing and modelling variograms and kriging. CATENA 113, 56-69. doi:10.1016/j.catena.2013.09.006

Ouyang, W., Xu, Y., Hao, F., Wang, X., Siyang, C., Lin, C., 2013. Effect of long-term agricultural cultivation and land use conversion on soil nutrient contents in the Sanjiang Plain. CATENA 104, 243-250. doi:10.1016/j.catena.2012.12.002

Paloscia, S., Macelloni, G., Santi, E., 2006. Soil Moisture Estimates From AMSR-E Brightness Temperatures by Using a Dual-Frequency Algorithm. IEEE Transactions on Geoscience and Remote Sensing 44, 3135-3144. doi:10.1109/TGRS.2006.881714

Qi, J., Chehbouni, A., Huete, A.R., Kerr, Y.H., Sorooshian, S., 1994. A modified soil adjusted vegetation index. Remote Sensing of Environment 48, 119-126. doi:10.1016/00344257(94)90134-1

R. Development Core Team, 2014. R: A Language and Environment for Statistical Computing. R Foundation for Statistical Computing, Vienna, Austria.

Rikimaru, A., Miyatake, S., 1997. Development of forest canopy density mapping and monitoring model using indices of vegetation, bare soil and shadow. Available at http:I www. gisdevelopment. net/aars/acrs/1997/ts5/index. shtmm.

Rock, B.N., Vogelmann, J.E., Williams, D.L., Vogelmann, A.F., Hoshizaki, T., 1986. Remote Detection of Forest Damage. BioScience 36, 439-445. doi:10.2307/1310339

Rogers, A.S., Kearney, M.S., 2004. Reducing signature variability in unmixing coastal marsh Thematic Mapper scenes using spectral indices. International Journal of Remote Sensing 25, 2317-2335. doi:10.1080/01431160310001618103

Rouse, J.W., Haas, R.H., Schell, J.A., Deering, D.W., 1974. Monitoring Vegetation Systems in the Great Plains with Erts. NASA Special Publication 351, 309.

Samuel-Rosa, A., Heuvelink, G.B.M., Vasques, G.M., Anjos, L.H.C., 2015. Do more detailed environmental covariates deliver more accurate soil maps? Geoderma 243-244, 214-227. doi:10.1016/j.geoderma.2014.12.017

Schmid, T., Koch, M., DiBlasi, M., Hagos, M., 2008. Spatial and spectral analysis of soil surface properties for an archaeological area in Aksum, Ethiopia, applying high and medium resolution data. CATENA 75, 93-101. doi:10.1016/j.catena.2008.04.008

Sims, D.A., Gamon, J.A., 2002. Relationships between leaf pigment content and spectral reflectance across a wide range of species, leaf structures and developmental stages. Remote Sensing of Environment 81, 337-354. doi:10.1016/S0034-4257(02)00010-X

Song, C., Jia, L., Menenti, M., 2014. Retrieving High-Resolution Surface Soil Moisture by Downscaling AMSR-E Brightness Temperature Using MODIS LST and NDVI Data. IEEE Journal of Selected Topics in Applied Earth Observations and Remote Sensing 7, 935-942. doi:10.1109/JSTARS.2013.2272053

Sreedevi, T., Shiferaw, B., Wani, S., 2004. Adarsha Watershed in Kothapally Understanding the Drivers of Higher Impact: Global Theme on Agroecosystems Report no. 10.

Srinivasarao, C., Venkateswarlu, B., Lal, R., Singh, A.K., Kundu, S., 2013. Chapter Five Sustainable Management of Soils of Dryland Ecosystems of India for Enhancing Agronomic Productivity and Sequestering Carbon, in: Sparks, D.L. (Ed.), Advances in Agronomy. Academic Press, pp. 253-329. 
Srinivasarao, C., Vittal, K.P.R., Venkateswarlu, B., Wani, S.P., Sahrawat, K.L., Marimuthu, S., Production Systems in Tropical India. Communications in Soil Science and Plant Analysis 40, 2338-2356. doi:10.1080/00103620903111277

Sumfleth, K., Duttmann, R., 2008. Prediction of soil property distribution in paddy soil landscapes using terrain data and satellite information as indicators. Ecological Indicators 8, 485-501. doi:10.1016/j.ecolind.2007.05.005

Sun, W., Minasny, B., McBratney, A., 2012. Analysis and prediction of soil properties using local regression-kriging. Geoderma 171-172, 16-23. doi:10.1016/j.geoderma.2011.02.010

van der Meer, F., 2004. Analysis of spectral absorption features in hyperspectral imagery. International Journal of Applied Earth Observation and Geoinformation 5, 55-68. doi:10.1016/j.jag.2003.09.001

Vaudour, E., Bel, L., Gilliot, J.M., Coquet, Y., Hadjar, D., Cambier, P., Michelin, J., Houot, S., 2013. Potential of SPOT Multispectral Satellite Images for Mapping Topsoil Organic Carbon Content over Peri-Urban Croplands. Soil Science Society of America Journal 77, 2122. doi:10.2136/sssaj2013.02.0062

Venkanna, K., Mandal, U.K., Raju, A., Sharma, K., Adake, R.V., Pushpanjali, B., Reddy, B.S., Masane, R.N., Venkatravamma, K., Babu, B., 2014. Carbon stocks in major soil types and land-use systems in semiarid tropical region of southern India. CURRENT SCIENCE 106, 604-611.

Webster, R., Oliver, M.A., 2001. Geostatistics for environmental scientists (Statistics in Practice).

Weng, Q., Fu, P., Gao, F., 2014. Generating daily land surface temperature at Landsat resolution by fusing Landsat and MODIS data. Remote Sensing of Environment 145, 55-67. doi:10.1016/j.rse.2014.02.003

Wolf, A., 2010. Using WorldView 2 Vis-NIR MSI imagery to support land mapping and feature extraction using normalized difference index ratios. Presented at the Proc. SPIE.

Xu, Y., Smith, S.E., Grunwald, S., Abd-Elrahman, A., Wani, S.P., 2017. Incorporation of satellite remote sensing pan-sharpened imagery into digital soil prediction and mapping models to characterize soil property variability in small agricultural fields. ISPRS Journal of Photogrammetry and Remote Sensing 123, 1-19. doi:10.1016/j.isprsjprs.2016.11.001 
Table 1 Description of Soil Samples.

\begin{tabular}{|c|c|c|}
\hline & Kothapally & Masuti \\
\hline Soil types & Vertisols & Vertisols, Entisols \\
\hline Crop types & $\begin{array}{l}\text { Major types: Cotton, rice, sorghum } \\
\text { Other types: Beet, bitter gourd, eggplant, } \\
\text { carrot, chiles, chickpea, cucumber, } \\
\text { coriander, flowers, limes, maize, mango, } \\
\text { okra, onion, potato, pigeon pea, turmeric, } \\
\text { safflower, tomato }\end{array}$ & $\begin{array}{l}\text { Major types: Cotton, rice, maize, sorghum, } \\
\text { tomato, onion } \\
\text { Other types: Banana, chickpea, eggplant, } \\
\text { groundnut, millet, onion, pigeon pea, } \\
\text { peanut, sugarcane, safflower, sunflower, } \\
\text { wheat }\end{array}$ \\
\hline Land use & Grassland land, fallow land, farmland & $\begin{array}{l}\text { Forest Land, fallow land, grassland, bare } \\
\text { land, farmland }\end{array}$ \\
\hline Soil color & $\begin{array}{l}\text { dark greyish brown, dark brown, dark } \\
\text { reddish brown }\end{array}$ & $\begin{array}{l}\text { dark greyish brown, dark brown, dark } \\
\text { reddish brown }\end{array}$ \\
\hline Tillage methods & Rainfed, Irrigation & Rainfed, Irrigation \\
\hline
\end{tabular}

Table 2. Environmental variables from remote sensing images.

\begin{tabular}{lll}
\hline Remote sensing images (acquisition date) & Abbreviation & Spatial resolution (m) \\
\hline Kothapally & & \\
Landsat 8 image (2013-4-13) & LTa & 30 \\
Landsat 8 image (2013-4-29) & LTb & 30 \\
RapidEye image (2010-4-19) & REa & 5 \\
RapidEye image (2013-2-24) & REb & 5 \\
WorldView-2 image (2011-12-14) & WVa & 2 \\
GeoEye-1 image (2011-1-21) & GE & 2 \\
Masuti & & \\
Landsat 8 image (2013-4-20) & LTc & 30 \\
Landsat 8 image (2013-5-22) & LTd & 30 \\
RapidEye image (2012-12-11) & REc & 5 \\
RapidEye image (2013-4-13) & REd & 5 \\
WorldView-2 image (2011-2-28) & WVb & 2 \\
Pleiades-1A image (2013-3-3) & PL & 2 \\
\hline
\end{tabular}

Bands of Landsat 8: Coastal, Blue, Green, Red, Near Infrared (NIR), Short Wavelength Infrared band 1, Short Wavelength Infrared band 2, Panchromatic, Cirrus, Long Wavelength Infrared band 1, Long Wavelength Infrared band 2

Bands of RapidEye: Blue, Green, Red, Red edge, NIR

Bands of WorldView-2: Coastal, Blue, Green, Yellow, Red, Red edge, NIR band1, NIR band2

Bands of GeoEye-1 and Pleiades-1A: Blue, Green, Red, NIR 
Table 3. Environmental variables from remote sensing images.

\begin{tabular}{|c|c|c|}
\hline Environmental Variables & Abbreviation & References \\
\hline Coastal band reflectance & Coastal & \\
\hline Blue band reflectance & Blue & \\
\hline Green band reflectance & Green & \\
\hline Yelllow band reflectance & Yellow & \\
\hline Red band reflectance & Red & \\
\hline Red edge band reflectance & Rededge & \\
\hline Near Infrared band reflectance & NIR & \\
\hline Near Infrared band 1 reflectance & NIR1 & \\
\hline Near Infrared band 2 reflectance & NIR2 & \\
\hline Short Wavelength band 1 reflectance & SWIR1 & \\
\hline Short Wavelength band 2 reflectance & SWIR2 & \\
\hline Green/Blue ratio & GB & \\
\hline Red/Blue ratio & $\mathrm{RB}$ & \\
\hline Red/Green ratio & RG & \\
\hline Red edge/Blue ratio & REB & \\
\hline Red edge/Green ratio & REG & \\
\hline Red edge/Red ratio & RER & \\
\hline NIR/Blue ratio & NB & \\
\hline NIR/Green ratio & NG & \\
\hline NIR/Red ratio & NR & \\
\hline NIR1/Blue ratio & N1B & \\
\hline NIR1/Green ratio & N1G & \\
\hline NIR1/Red ratio & N1R & \\
\hline NIR1/Red edge ratio & N1RE & \\
\hline NIR2/Blue ratio & N2B & \\
\hline NIR2/Green ratio & $\mathrm{N} 2 \mathrm{G}$ & \\
\hline NIR2/Red ratio & N2R & \\
\hline NIR2/Red edge & N2RE & \\
\hline NIR2/NIR1 ratio & $\mathrm{N} 2 \mathrm{~N} 1$ & \\
\hline SW1/Blue ratio & S1B & \\
\hline SW1/Green ratio & S1G & \\
\hline SW1/Red ratio & S1R & \\
\hline SW1/NIR ratio & S1N & \\
\hline SW2/Blue ratio & S2B & \\
\hline SW2/Green ratio & S2G & \\
\hline SW2/Red ratio & S2R & \\
\hline SW2/NIR ratio & S2N & \\
\hline SW2/SW1 ratio & $\mathrm{S} 2 \mathrm{~S} 1$ & \\
\hline Normalized Difference Vegetation Index & NDVI & (Rouse et al., 1974) \\
\hline Normalized Difference Green Index & NDVIg & (Gitelson et al., 1996) \\
\hline Simple Ratio & SR & (Cohen, 1991) \\
\hline Transformed Spectral Index & TVI & (Nellis and Briggs, 1992) \\
\hline Green Chlorophyll Index & $\mathrm{CIg}$ & (Gitelson et al., 2005) \\
\hline Soil Adjusted Vegetation Index & SAVI & (Qi et al., 1994) \\
\hline Atmospherically Resistant Vegetation Index & ARVI & (Kaufman and Tanré, 1996) \\
\hline Crust Index & $\mathrm{CI}$ & (Karnieli, 1997) \\
\hline Modified Chlorophyll Absorption in Reflectance Index & MCARI & (Daughtry et al., 2000) \\
\hline Red-edge Chlorophyll Index & $\mathrm{CIr}$ & (Gitelson et al., 2005) \\
\hline
\end{tabular}


Table 3. Continued.

\begin{tabular}{lll}
\hline Environmental Variables & $\begin{array}{l}\text { Abbreviation } \\
\text { Normalized Difference Red-edge Index }\end{array}$ & $\begin{array}{l}\text { References } \\
\text { (Gitelson and Merzlyak, 1994; } \\
\text { Sims and Gamon, 2002) }\end{array}$ \\
$\begin{array}{l}\text { Transformed Chlorophyll Absorption in Reflectance Index } \\
\text { Moisture Stress Index }\end{array}$ & TCARI & $\begin{array}{l}\text { (Haboudane et al., 2002) } \\
\text { (Rock et al., 1986) }\end{array}$ \\
Normalized Difference Water Index & NDWI & (Gao, 1996) \\
Mid-infrared Index & MidIR & (Musick and Pelletier, 1988) \\
Bare soil index & BSI & (Rikimaru and Miyatake, 1997) \\
Normalized Difference Soil Index & NDSI & (Rogers \& Kearney, 2004) \\
At-satellite brightness temperature for band 10 $(10.30-11.30 \mu \mathrm{m})(\mathrm{K})$ & T1 & \\
At-satellite brightness temperature for band $11(11.50-12.50 \mu \mathrm{m})(\mathrm{K})$ & T2 & \\
Elevation $(\mathrm{m})$ & Elevation & \\
Aspect (Degree) & Aspect & \\
Flow Accumulation & FlowAccu & \\
Flow Direction & FlowDir & \\
Slope (Degree) & Slope & \\
\hline
\end{tabular}

Table 4. Descriptive analysis of original and log-transformed TN

\begin{tabular}{lllllllllllll}
\hline Location & Transform & Data Type & $\mathrm{N}$ & Mean & Median & SD & Min & Max & Range & Skew & Kurtosis & CV \\
\hline Kothapally & & Total & 255 & 869 & 856 & 221 & 329 & 1821 & 1492 & 0.47 & 1.05 & 0.25 \\
& & Calibration & 179 & 874 & 856 & 222 & 400 & 1821 & 1421 & 0.63 & 1.37 & 0.25 \\
\multirow{4}{*}{ Masuti } & & Validation & 76 & 856 & 860 & 217 & 329 & 1507 & 1178 & 0.06 & -0.02 & 0.25 \\
& & Total & 259 & 514 & 487 & 186 & 166 & 1182 & 1016 & 0.59 & 0.14 & 0.36 \\
& & Calibration & 180 & 514 & 487 & 191 & 166 & 1182 & 1016 & 0.63 & 0.17 & 0.37 \\
& & Validation & 79 & 515 & 487 & 177 & 206 & 1059 & 853 & 0.47 & -0.12 & 0.34 \\
\hline \multirow{4}{*}{ Kothapally } & $\log _{10}(\mathrm{x})$ & Total & 255 & 2.92 & 2.93 & 0.11 & 2.52 & 3.26 & 0.74 & -0.46 & 0.53 & 0.04 \\
& $\log _{10}(\mathrm{x})$ & Calibration & 179 & 2.93 & 2.93 & 0.11 & 2.6 & 3.26 & 0.66 & -0.32 & 0.42 & 0.04 \\
& $\log _{10}(\mathrm{x})$ & Validation & 76 & 2.92 & 2.93 & 0.12 & 2.52 & 3.18 & 0.66 & -0.71 & 0.52 & 0.04 \\
Masuti & $\log _{10}(\mathrm{x})$ & Total & 259 & 2.68 & 2.69 & 0.16 & 2.22 & 3.07 & 0.85 & -0.3 & -0.25 & 0.06 \\
& $\log _{10}(\mathrm{x})$ & Calibration & 180 & 2.68 & 2.69 & 0.16 & 2.22 & 2.98 & 0.76 & -0.35 & -0.35 & 0.06 \\
& $\log _{10}(\mathrm{x})$ & Validation & 79 & 2.69 & 2.68 & 0.17 & 2.23 & 3.07 & 0.84 & -0.21 & -0.15 & 0.06 \\
\hline
\end{tabular}

Abbreviations: N, number of samples; SD, standard deviation; CV; coefficient of variation. 
Table 5. Linear correlations between soil TN and spectral indices different remote sensing images.

\begin{tabular}{|c|c|c|c|c|c|}
\hline \multicolumn{6}{|c|}{ Kothapally } \\
\hline Landsat 8 & & RapidEye & & WV and GE & \\
\hline Index & $\mathrm{R}$ & Index & $\mathrm{R}$ & Index & $\mathrm{R}$ \\
\hline LTbRG & -0.419 & REbRed & -0.429 & GECI & 0.475 \\
\hline LTbARVI & 0.409 & REbARVI & 0.421 & GERB & -0.475 \\
\hline LTaARVI & 0.397 & $\mathrm{REbCI}$ & 0.412 & GERed & -0.474 \\
\hline LTbCI & 0.390 & REbRB & -0.412 & GERG & -0.440 \\
\hline LTbRB & -0.390 & REbRG & -0.404 & GEBlue & -0.395 \\
\hline LTaRG & -0.373 & REbBlue & -0.387 & WVaCI & 0.393 \\
\hline LTbT2 & -0.373 & REbNDVIr & 0.385 & WVaRB & -0.393 \\
\hline LTbT1 & -0.368 & REbCIr & 0.385 & GEGreen & -0.390 \\
\hline LTaCI & 0.364 & REbNRE & 0.385 & WVaRG & -0.372 \\
\hline LTaRB & -0.364 & REaARVI & 0.381 & GEARVI & 0.351 \\
\hline LTbRed & -0.353 & REbNDVI & 0.367 & WVaRed & -0.325 \\
\hline LTaRed & -0.339 & REbSR & 0.367 & WVaYellow & -0.318 \\
\hline LTbBSI & -0.318 & REbTVI & 0.367 & GENDVI & 0.262 \\
\hline LTaT1 & -0.309 & REbNR & 0.367 & GESR & 0.262 \\
\hline LTaMidIR & 0.289 & REbGreen & -0.364 & GETVI & 0.262 \\
\hline \multicolumn{6}{|c|}{ Masuti } \\
\hline Landsat 8 & & RapidEye & & WV and PL & \\
\hline Index & $\mathrm{R}$ & Index & $\mathrm{R}$ & Index & $\mathrm{R}$ \\
\hline LTcARVI & 0.481 & REcCI & 0.414 & WVbCI & 0.45 \\
\hline LTcRG & -0.481 & REcRB & -0.414 & WVbRB & -0.45 \\
\hline LTcBSI & -0.478 & REcRededge & -0.388 & PLRG & -0.44 \\
\hline LTdRG & -0.465 & REcRed & -0.379 & PLCI & 0.437 \\
\hline LTdCI & 0.454 & REdRededge & -0.371 & PLRB & -0.437 \\
\hline LTdRB & -0.454 & REdCI & 0.368 & PLRed & -0.424 \\
\hline LTcCI & 0.45 & REdRB & -0.368 & WVbRG & -0.417 \\
\hline LTcRB & -0.45 & REcREB & -0.365 & WVbRed & -0.405 \\
\hline LTdBSI & -0.447 & REcGreen & -0.351 & WVbYellow & -0.402 \\
\hline LTcRed & -0.442 & REdRed & -0.346 & PLGB & 0.397 \\
\hline LTdARVI & 0.441 & REcGB & -0.344 & PLBlue & -0.384 \\
\hline LTdRed & -0.441 & REdGreen & -0.339 & WVbN2RE & 0.381 \\
\hline LTcSWIR2 & -0.432 & REcARVI & 0.338 & WVbARVI & 0.379 \\
\hline LTcNDWI & 0.416 & REcRG & -0.335 & PLARVI & 0.376 \\
\hline LTcMSI & -0.416 & REdGB & -0.32 & PLGreen & -0.369 \\
\hline
\end{tabular}

Nomenclature of the variables in Table 5: Remote Sensing Image (Abbreviations in Table 2) + Spectral Index (Abbreviations in Table 3). All the spectral indices in Table 5 show significant correlations with soil TN $(\mathrm{p}<0.05)$. 
Table 6. Multi-linear regression model of soil TN.

\begin{tabular}{|c|c|c|c|}
\hline Model & Multi-linear regression model & $\begin{array}{l}\text { Spatial } \\
\text { resolution }(\mathrm{m})\end{array}$ & $\mathrm{R}^{2}$ \\
\hline K1 & $\log \mathrm{TN}=6.09+1.02 * \mathrm{LTbCI}-0.014 * \mathrm{LTbT} 2+0.07 * \mathrm{LTbS} 2 \mathrm{~B}-0.008 *$ Slope & 30 & 0.22 \\
\hline $\mathrm{K} 2$ & $\log \mathrm{TN}=3.16+0.21 * \mathrm{REaARVI}-0.08 * \mathrm{REbRed}+0.59 * \mathrm{REbCI}$ & 5 & 0.21 \\
\hline K3 & $\log \mathrm{TN}=2.19+0.77 * \mathrm{GECI}-0.01 *$ Slope $+1.45 * \mathrm{WVaBlue}+0.37 * \mathrm{WVaNDVIr}$ & 2 & 0.26 \\
\hline M1 & $\log \mathrm{TN}=5.90+0.44 * \mathrm{LTcARVI}+0.15 * \mathrm{LTcBSI}-0.89 * \mathrm{LTcSWIR} 1-0.01 * \mathrm{LTcT} 1$ & 30 & 0.24 \\
\hline M2 & $\log \mathrm{TN}=2.77-0.23 * \mathrm{REcRB}+0.19 * \mathrm{REcGB}-0.13 *$ REcRededge+0.15*REcARVI & 5 & 0.20 \\
\hline M3 & $\log \mathrm{TN}=1.13+1.02 * \mathrm{WVbCI}+0.69 * \mathrm{WVbN} 2 \mathrm{RE}-0.73 * \mathrm{WVbCIr}$ & 2 & 0.31 \\
\hline
\end{tabular}

Table 7. Model validation results of Regression Kriging models for TN.

\begin{tabular}{lllll}
\hline Model & Adj R & $\begin{array}{l}\text { RMSE } \\
\left(\mathrm{mg} \mathrm{kg}^{-1}\right)\end{array}$ & RPD & $\begin{array}{l}\text { Spatial } \\
\text { resolution }(\mathrm{m})\end{array}$ \\
\hline KR1 & 0.28 & 179.46 & 1.16 & 30 \\
KR2 & 0.36 & 167.89 & 1.24 & 5 \\
KR3 & 0.42 & 159.36 & 1.31 & 2 \\
MR1 & 0.48 & 146.24 & 1.33 & 30 \\
MR2 & 0.41 & 148.70 & 1.30 & 5 \\
MR3 & 0.56 & 130.73 & 1.49 & 2 \\
\hline
\end{tabular}



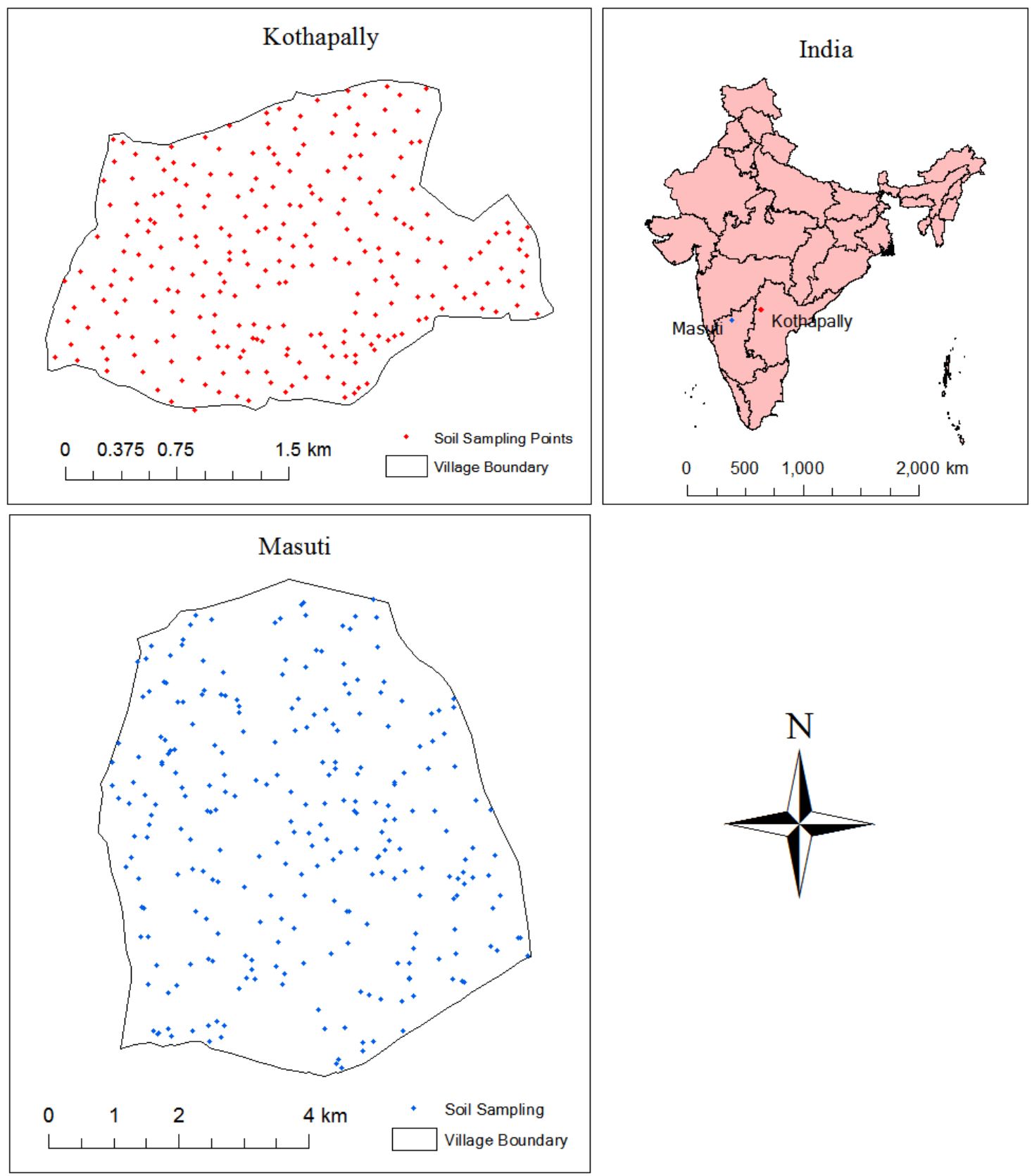

Fig. 1. The boundary and soil samplings of Kothapally and Masuti Village. 


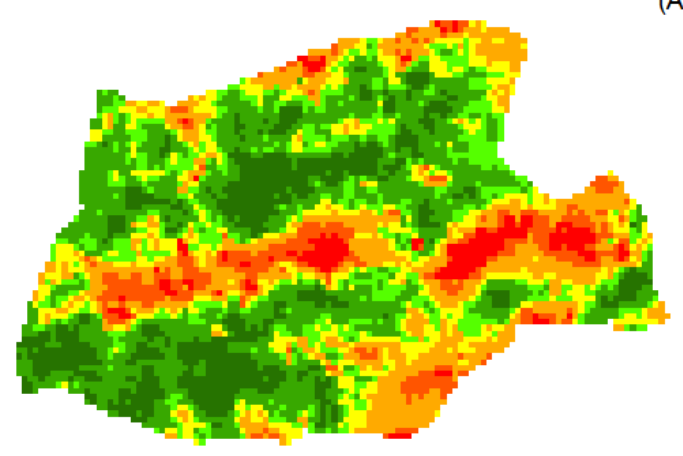

(A)
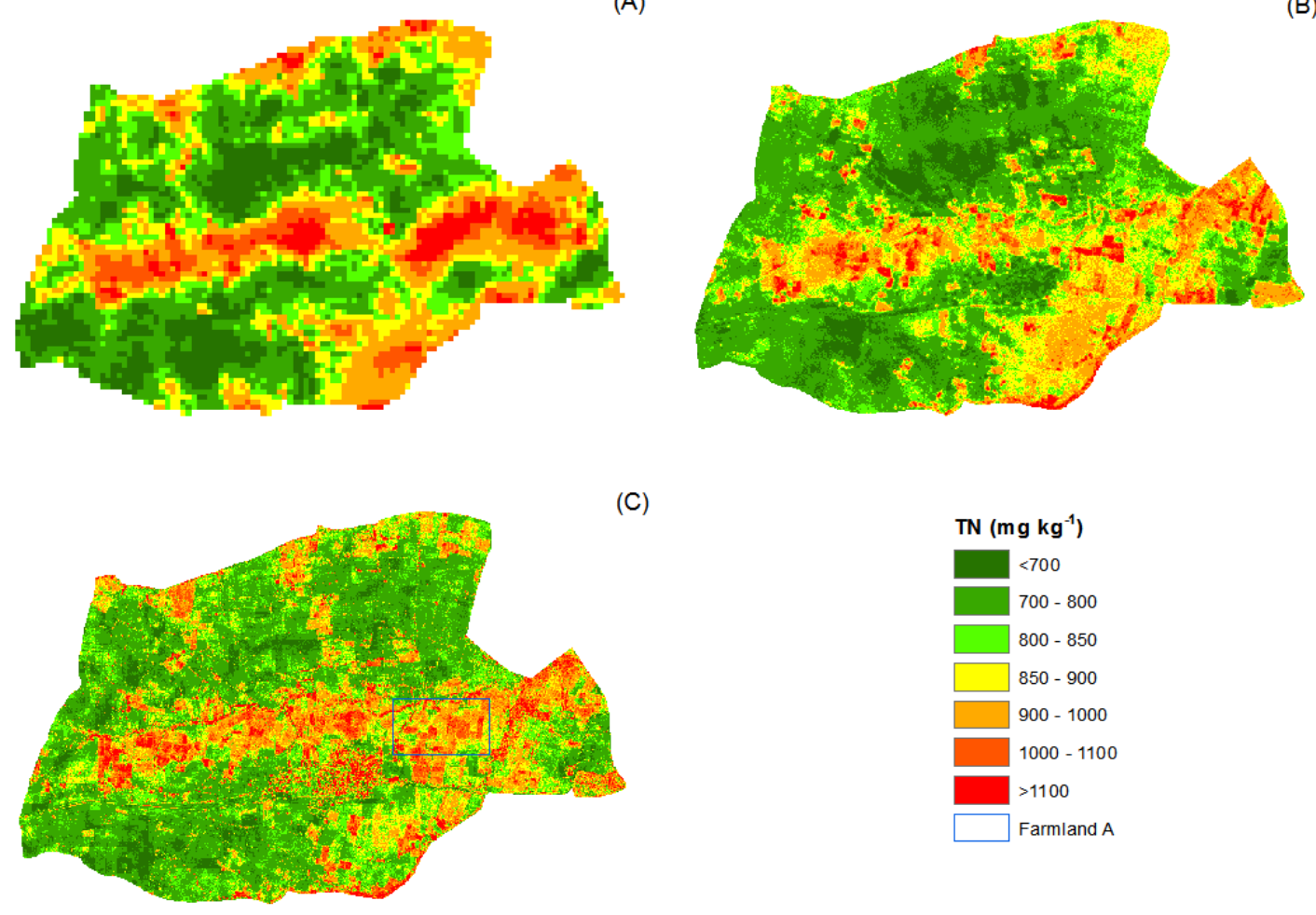

(C)
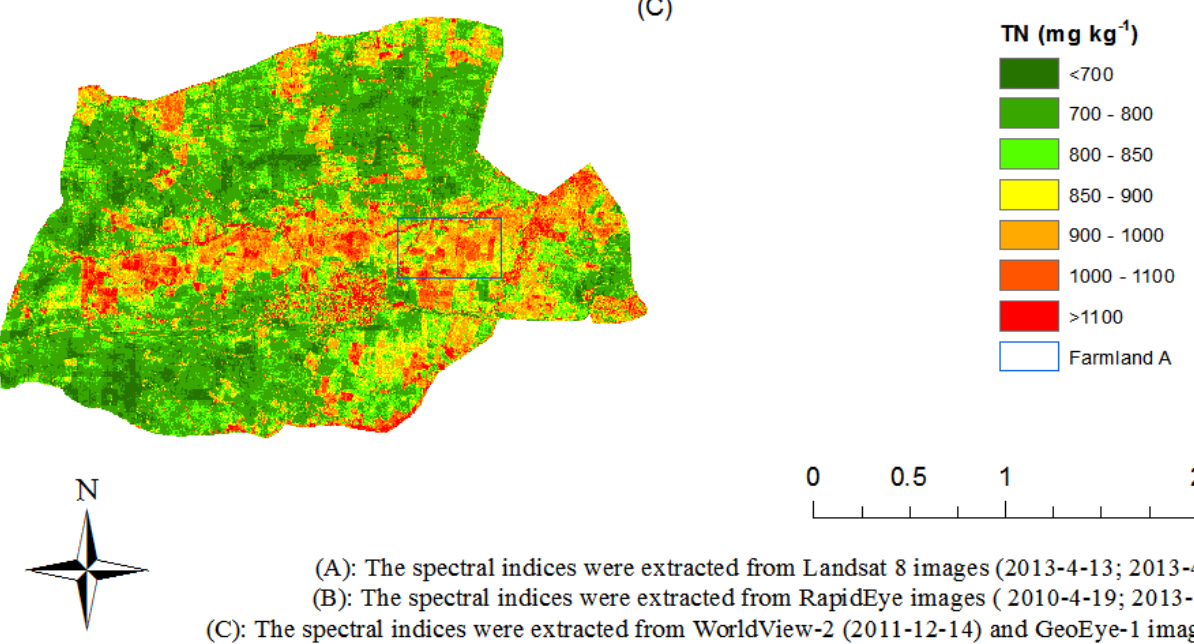

(A): The spectral indices were extracted from Landsat 8 images (2013-4-13; 2013-4-29).

(B): The spectral indices were extracted from RapidEye images (2010-4-19; 2013-2-24).

(C): The spectral indices were extracted from WorldView-2 (2011-12-14) and GeoEye-1 images (2012-1-21).

Fig. 2. Soil total nitrogen (TN) prediction at $0-15 \mathrm{~cm}$ depth in Kothapally from (A) Model KR1: Regression kriging of TN based Landsat 8 images; (B) Model KR2: Regression kriging model of TN based on RapidEye images; (C) Model KR3: Regression kriging model of TN based on WorldView-2 and GeoEye-1 images. 
(A)

(B)
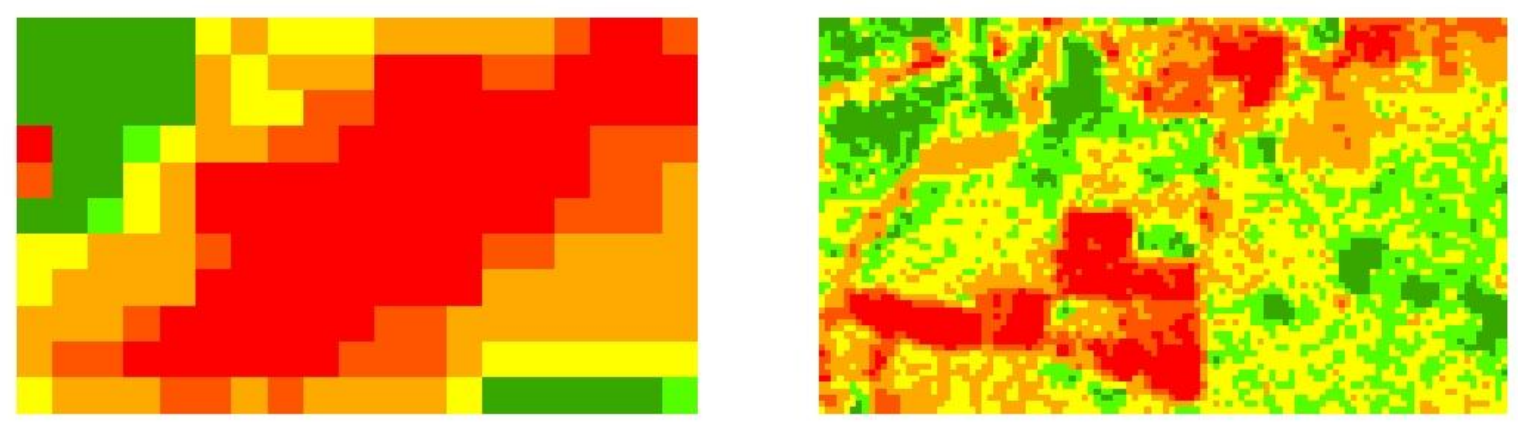

(C)

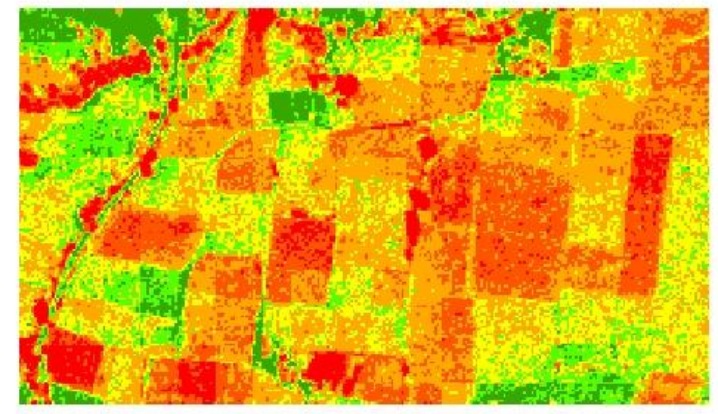

\section{$\mathrm{TN}\left(\mathrm{mg} \mathrm{kg}^{-1}\right)$}
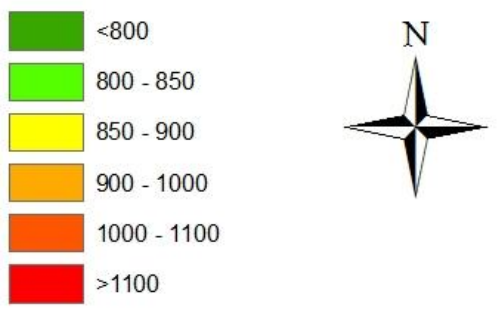

0

100200

$400 \mathrm{~m}$

(A): The spectral indices were extracted from Landsat 8 images (2013-4-13; 2013-4-29).

(B): The spectral indices were extracted from RapidEye images (2010-4-19;2013-2-24).

(C): The spectral indices were extracted from WorldView-2 (2011-12-14) and GeoEye-1 images (2012-1-21).

Fig. 3 Soil TN prediction at $0-15 \mathrm{~cm}$ depth in Farmland A from (A) Model KR1; (B) Model KR2; (C) Model KR3 in Kothapally. 
(A)

(B)
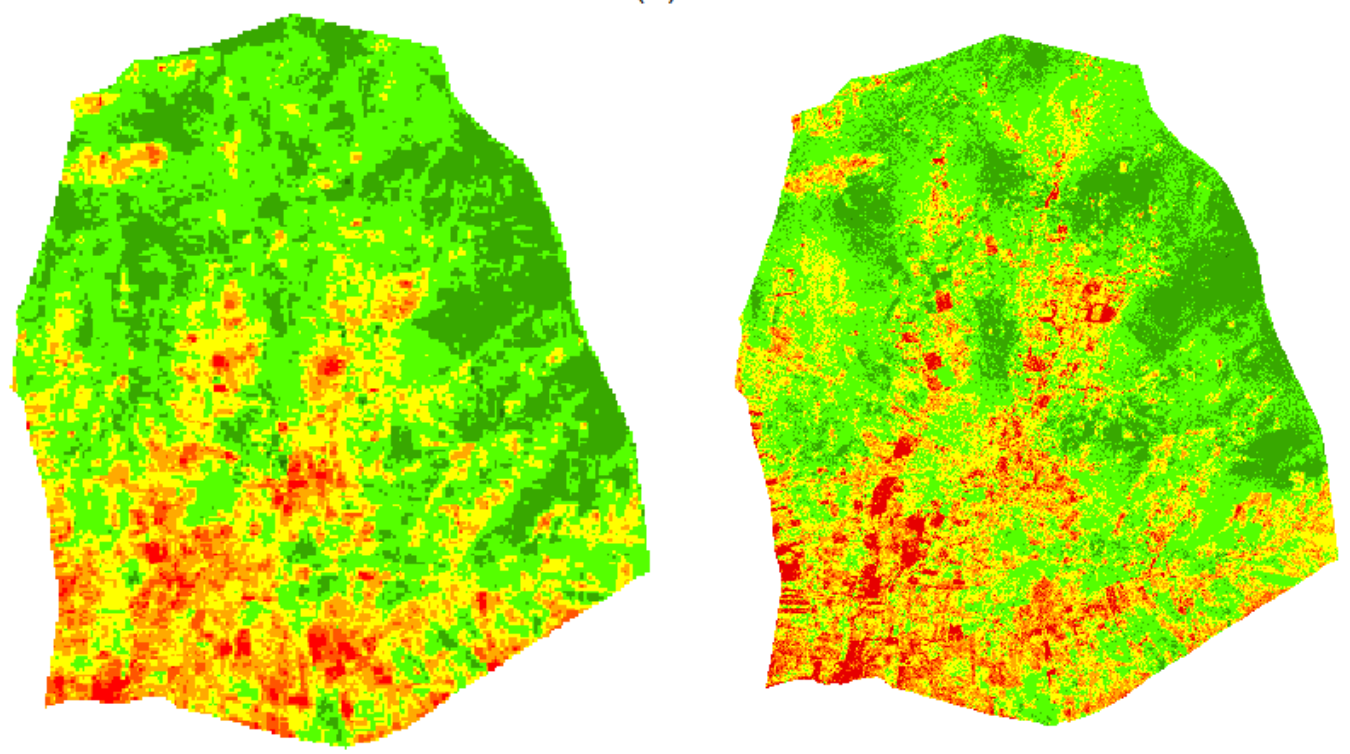

(C)
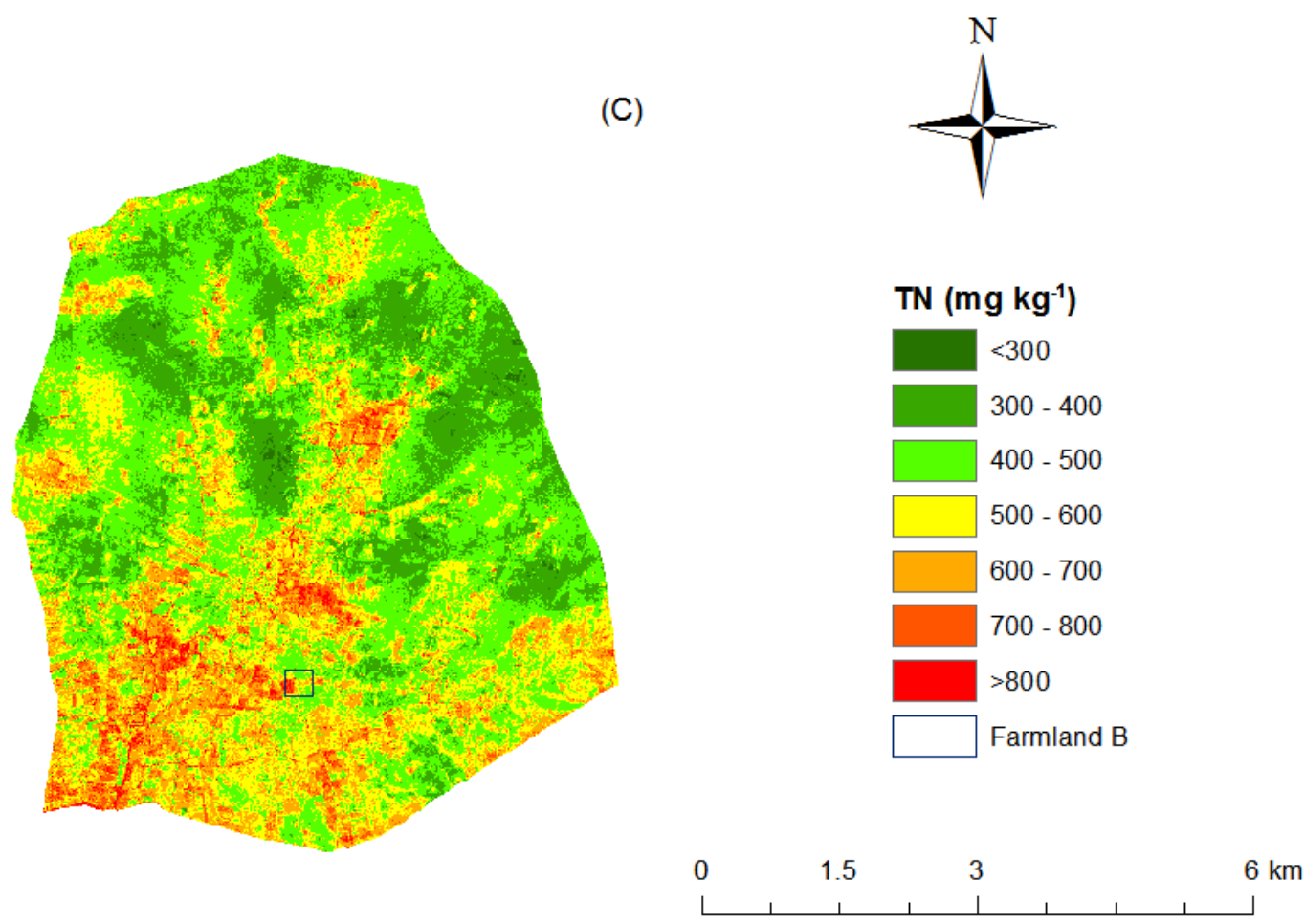

(A): The spectral indices were extracted from Landsat 8 images (2013-04-20; 2013-05-22).

(B): The spectral indices were extracted from RapidEye images (2012-12-11; 2013-1-5).

(C): The spectral indices were extracted from WorldView-2(2011-2-28) and Pleiades-1A (2013-3-3).

Fig. 4. Soil TN prediction at $0-15 \mathrm{~cm}$ depth in Masuti from (A) Model MR1: Regression kriging of TN based Landsat 8 images; (B) Model MR2: Regression kriging model of TN based on RapidEye images; (C) Model MR3: Regression kriging model of TN based on WorldView-2 and Pleiades-1A images. 
(A)

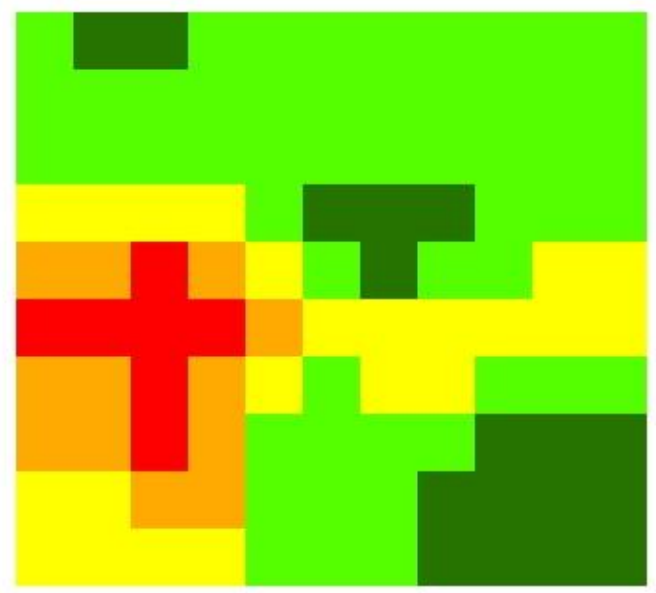

(C)

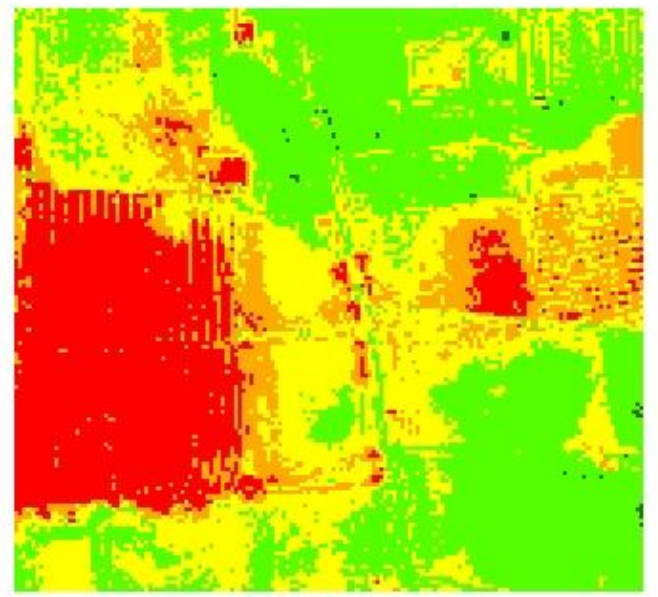

(B)

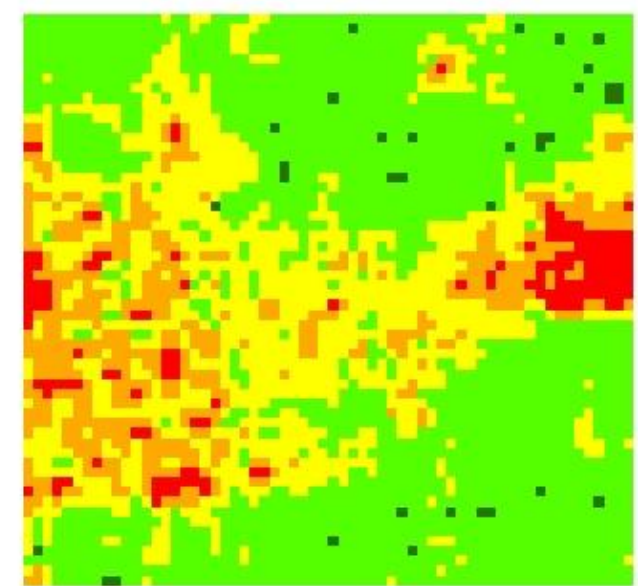

